\title{
STUDY ON VALUE-BASED MODEL OF PRODUCTS PACKAGE MANAGEMENT
}

\author{
Ying Liu ${ }^{1}$, Fengming $\mathrm{Tao}^{2}$ and Fei Liu ${ }^{1}$ \\ ${ }^{\prime}$ College of Mechanical Engineering, Chongqing University, China, 400044; Email: \\ lyjfb@xinhuanet.com. ${ }^{2}$ College of Economics \& Business Administration Chongqing \\ University, China, 400044
}

Abstract: $\quad$ Package management is an important part of supply chain management. This paper analyzed the different levels of the value of package and the structure of the value chains in products package management. A value-based model of products package management was brought forth and the key technologies of package management were discussed.

Key words: value; package management; supply chains; green manufacturing

Today the importance of products package has been recognized by the society and firms. In some industries, the package can even decide whether the product can be popular ${ }^{[1]}$.Package management is the important chain in supply chains. Even though product packaging improves marketing a lot, package management is comparatively new in China and very few researches on the value weight of package management in supply chain and on the control model of package management. Problems of package have made huge economic loss and environment pollution. The value-based package management is the optimization of value chain and human-centered.

\section{PACKAGE AND PACKAGE MANAGEMENT}

- Concept and classification of package

The function of package is to protect and beatify products so to increase their add value. Besides, it can act as advertisement to trigger consumers' interest and motivate them to buy products.

According to the shape of package, it can be classified as single package, inside package and outside package; according to the location of supply

Please use the following format when citing this chapter:

Liu, Ying, Tao, Fengming, Liu, Fei, 2006, in International Federation for Information Processing (IFIP), Volume 207, Knowledge Enterprise: Intelligent Strategies In Product Design, Manufacturing, and Management, eds. K. Wang, Kovacs G., Wozny M., Fang M., (Boston: Springer), pp. 356-362. 
chain, it can be classified as business package and industrial package; according to the material, it can be classified as wooden box, paper box, and glass container, and package of plastic, cloth, hemp rope, metal, plant and etc.; according to the ways of package, it can be classified as water-proof, wet-proof, rust-proof, vacuum, decompression, fire-proof, frozen, gas-proof, explosion-proof and etc.

- Package management

Package management is the sum of several act including design, manufacturing, delivery and use of package so that consumers can be guaranteed to totally, conveniently and accurately get and take the value of the product. In a broad sense, package management does not only mean the manufacturing, encapsulation and usage of package itself, instead, it concerns the management of design, logistics, marketing and recycling of package.

\section{THE VALUE SYSTEM OF PACKAGE}

There are three levels in the value system of package(figure 1).

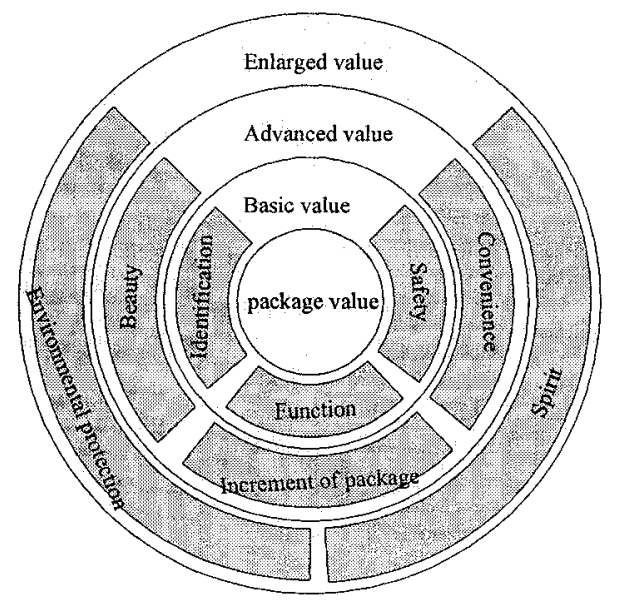

Figure 1. Levels of package value

\subsection{Basic value}

It is the core of package:

- Function of package: package protect production from leakage, stealing, fresh keeping and so on. 
- Identification of package: good package can explain the function of products and trigger consumers' interest to buy.

- Safety of package: package itself must be safe, which protect products from damage and protect users safe as well.

\subsection{Advanced value}

It is essential to complete and increase the value of package so that value added can be gained.

- Beauty of package: beautiful and practical package can attract consumers' attention and help products gain better benefit.

- Increment of package: if cost and wastage of package is reduced, recycle rate is increased and management flow is amended, the value of products package can be increased, better economic benefit can be obtained.

- Convenience of package: some kind of convenience can be get from package so that the convenience of product storage, transportation, sale and usage can be realized.

\subsection{Enlarged value}

It is essential to expand the value of package so that the responsibility of product package toward consumers and society can be completed.

- Environmental protection of package: products package and the industry must be green, they must deal the recycling and wastes in a right way.

- Spirit of package: as the clothes of products, package can be the important carrier of brand value. It can describe the concepts of products and show the taste of products. Some of them even become one part of the firm culture, for instance, the bottle of Coca Cola.

\section{VALUE CHAIN OF PACKAGE MANAGEMENT}

The value of package exists in every unit of the "supply chain" of package. Such a chain consists of package design, package manufacturing, package encapsulation, package transportation, marketing, after sale service and so on. All the firms, organizations and individuals concerned can benefit from this supply chain of products package, hence, they shape the value chain of products package.According to the degree of cooperation among package users, suppliers and sellers and the influence on the value chain, we can divide the units of the chain into three groups as follows.

- Core value units. This units main refer to the firms that use products package. Two kinds of firms belong to this group: firms manufacturing products; and sellers re-packaging products. They are responsible for the 
organizing and management of the supply chain, resolving conflicts among units and maximizing the value of the chain.

- Alliance value units. These units include the firms responsible for design, manufacturing, supply and transportation of package. They provide service to the core value units and get benefit from it.

- After sale value units. These units are responsible for the recycling and waste dealing of products package. This kind of firms are very special because most of them are under government's control and only a very few firms that use products package involve in the recycling. However, with the popularization of environmental protection and the advance of waste dealing, package recycling and re-use is becoming a new industry with great potential value.

\section{VALUE-BASED MODEL OF PACKAGE MANAGEMENT}

\subsection{Puzzles}

- Integration of elements

In value system of products package, eight elements are relative and at the same time contradictory. For example, the value increment of package and environmental protection of products package are always contradictory. Therefore, when considering a certain product package, it is necessary to compare all the eight elements and determine the weight of each one according to actual situation, and hence receive an optimal plan.

- Management and balance of the value chain

Along the value chain, core value units, alliance value units and after sale value units have respectively their own value and benefits. All the value and benefits might be conflict, so it is essential to establish a system to manage and balance their interests and benefits.

\subsection{Value-based model of package management}

Aimed to the puzzles, this paper put forward the Value-based model of package management (figure 2). The model is composed of three levels.

\subsubsection{Package value system level}

The concrete contents in this level consist of four parts.

- Principles of package value management. They include principles of standard generalization of package, principles of innovation, principles of 
moderation, principles of intensivism, principles of economy and principles of recycling and re-use.

- Weight evaluation and strategies of package value management. When considering a certain product package with limiting factors, it is necessary to compare all the eight elements and determine the weight of each one, and hence receive an optimal plan. Based on the optimal plan, a suitable strategy can be obtained. The weight evaluation and strategies of package value management should be completed by the core value units who must quickly feedback and adjust the plan and strategies when limiting factors change.

- Balance mechanism for different value units. Along the value chain, core value units, alliance value units and after sale value units have respectively their own value and benefits. All the value and benefits might be conflict, so for the core value units, it is essential to establish a system to manage and balance their interests and benefits. With such a mechanism, the construct of the value chain and modes of process; interests distribution and coordination along the chain; and control mechanism in package management can be settled down.

- Standards and policies of products package. There are a series of national and international standards and policies, such as international environment standards in ISO14000. If products package did not meet the standards or policies, the manufacturing and sale of products would be limited and great economic loss would happen. Therefore, the package management must have the direction of standards and principles.

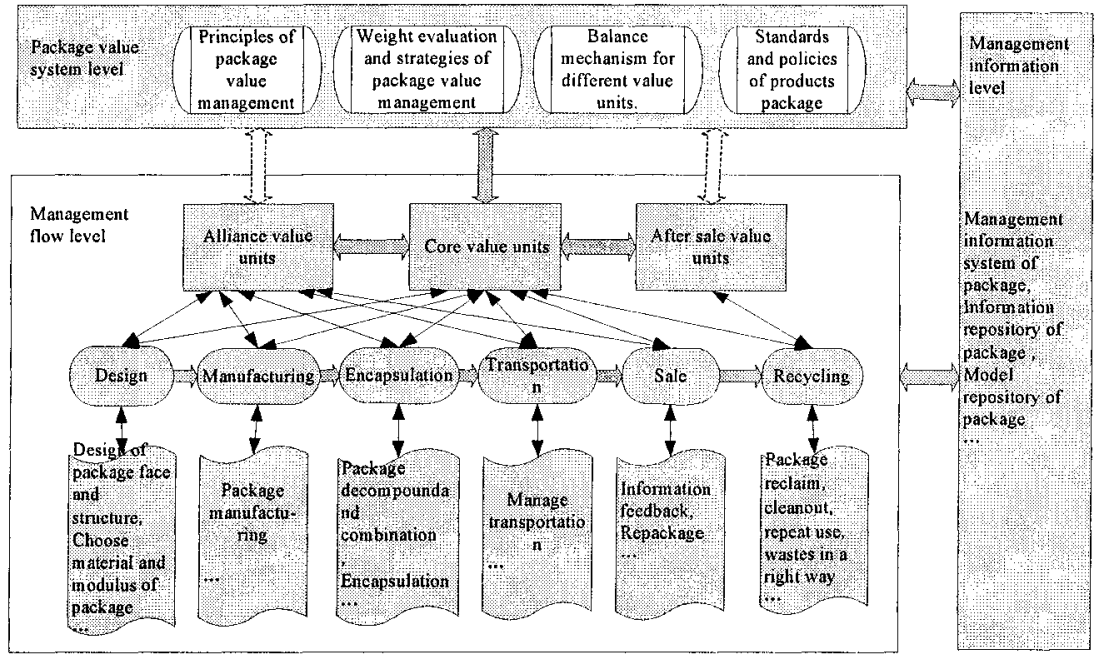

Figure 2. Value-based model of package management 


\subsubsection{Management flow level}

Management flow level is the process of concrete management and control of the supply chain of products package. It is a course including design, manufacturing, encapsulation, transportation, sale and recycling. In this flow, core value units, alliance value units and after sale value units separately complete their duties and gain their benefits under the direction of the strategies and plans of products package. The key points are as following.

- The core value units must hold the overall situation, obtain dynamic information, constitute the flow model and guild the process of the flow.

- Core value units, alliance value units and after sale value units are closely tied up and they action and information are tightly related.

- There are sub-circles in the management flow such as multi-package and disassembly. For instance, disassembling packages in transportation and repackage in business promotion.

\subsubsection{Management information level}

This level is made up of management information system of package, information repository of package and model repository of package. By the ways of internet and other network, information coding management, information management of management flow, management of information repository, consumer management and computer modeling, the information in the supply chain of package can be collected, summarized and managed. Consequently, the value units and consumers can get and communicate information and consultation and solve plan can be obtained.

In the three levels above, package value level provides the valuebased plan, management flow level implements the plan, and management information level offers information and service to the two levels. The three levels influence each other and constitute the management model together.

\section{KEY TECHNOLOGIES}

- The value chain of package management and its control strategies. In order to obtain the optimal strategies, the value units must analyze the relationship among them and build up the cooperation mechanism and control mechanism.

- The value-based package design. Package design is so important that more than $40 \%$ successful packages resulted from good designs. The value-based package design considers the structure design, reasonable 
economic materials, beautiful and practical appearance design, function design and storage design ${ }^{[2]}$, and etc.

- Innovation of material and structure of package. The usage and development of new material and new structure of package can improve the function and reduce cost, and attract customers to buy.

- Green package and its management technologies. Green package and its management technologies constitute the suitable layer management, simplifying sectors of packaging and integration, green design, usage and development of green material, recycling and re-use of package and degradation technologies of wastes ${ }^{[3]}$.

- Information management and tracing. It constitutes the classification and encoding technologies of information, extraction technologies of information, information transportation and integration, information tracing technologies and information repository and model repository and so on ${ }^{[4]}$.

\section{CONCLUSION}

Aimed to increase the comprehensive value of the "supply chain" of products package, the value-based package management integrated multiknowledge, value chain and value units network, green package and information management together. And the kernel of the value-based package management is the optimization of value chain and human-centered. This kind of package management can increase the value of packages and has a bright future. The development of package industry will promote the value-based package management to a better improvement.

\section{REFERENCES}

1. C. F.Dong, Y. He, How Chinese package firms improve their international competitive capacity, Package Engineering. (2004), 32 (6), 165-167

2. F. Liu, H. Zhang, H.H. Yue, Green manufacturing: The model of sustainable development for modern manufacturing, Chinese Mechanical Engineering. (1998), 9(6): 76-78

3. H. M. Dai, Theory, standard and manufacturing model of green package, Chinese Mechanical Engineering. (2002), 23(13): 2048-2052

4. G. B. Jin, Intelligent package technologies and the development, Chinese Package. (2002), (5): $37-41$. 